\title{
Epidemiology of Rare Hereditary Diseases in the European Part of Russia: Point and Cumulative Prevalence
}

\author{
Rena A. Zinchenko ${ }^{1,2 *}$, Eugeny K. Ginter ${ }^{1}$, Andrey V. Marakhonov ${ }^{*}$, Nika V. Petrova ${ }^{1}$, \\ Vitaly V. Kadyshev ${ }^{1}$, Tatyana P. Vasilyeva ${ }^{2}$, Oksana U. Alexandrova ${ }^{2}$, \\ Alexander V. Polyakov ${ }^{1}$ and Sergey I. Kutsev ${ }^{1}$
}

'Research Centre for Medical Genetics, Moscow, Russia, ${ }^{2}$ Department of Public Health Research, N.A. Semashko National Research Institute of Public Health, Moscow, Russia

OPEN ACCESS

Edited by:

Elvira Galieva,

Novosibirsk State University, Russia

Reviewed by:

Feng Zhang,

Fudan University, China

Evgenii Chekalin

Michigan State University,

United States

Nina Oparina

University of Gothenburg, Sweden

Milan Macek

Charles University, Czechia

*Correspondence:

Rena A. Zinchenko

renazinchenko@mail.ru

Andrey V. Marakhonov

marakhonov@generesearch.ru

Specialty section

This article was submitted to Evolutionary and Population Genetics,

a section of the journal

Frontiers in Genetics

Received: 10 March 2021

Accepted: 15 July 2021

Published: 30 August 2021

Citation:

Zinchenko RA, Ginter EK, Marakhonov AV, Petrova NV, Kadyshev W, Vasilyeva TP, Alexandrova OU, Polyakov AV and

Kutsev SI (2021) Epidemiology

of Rare Hereditary Diseases in the European Part of Russia: Point

and Cumulative Prevalence.

Front. Genet. 12:678957.

doi: 10.3389/fgene.2021.678957
The issue of point prevalence, cumulative prevalence (CP), and burden of rare hereditary diseases (RHD), comprising $72-80 \%$ of the group of rare diseases, is discussed in many reports and is an urgent problem, which is associated with the rapid progress of genetic technology, the identification of thousands of genes, and the resulting problems in society. This work provides an epidemiological analysis of the groups of the most common RHDs (autosomal dominant, autosomal recessive, and X-linked) and their point prevalence (PP) and describes the structure of RHD diversity by medical areas in 14 spatially remote populations of the European part of Russia. The total size of the examined population is about 4 million. A total of 554 clinical forms of RHDs in 10,265 patients were diagnosed. The CP for all RHDs per sample examined was $277.21 / 100,000$ (1:361 people). It is worth noting that now is the time for characterizing the accumulated data on the point prevalence of RHDs, which will help to systematize our knowledge and allow us to develop a strategy of care for patients with RHDs. However, it is necessary to address the issues of changing current medical classifications and coding systems for nosological forms of RHDs, which have not kept pace with genetic advances.

Keywords: genetic epidemiology, rare hereditary diseases, point prevalence, cumulative prevalence, Russia

\section{INTRODUCTION}

The problem of rare diseases (RDs) and their number, birth, point, and cumulative prevalence are actively discussed by many researchers, and this is important for public health and society. Criteria for the definition of "rare diseases" differ from country to country depending on legislation. A review by Richter et al. (2015) provides data on 296 definitions of RDs from 1,109 organizations (Richter et al., 2015) and confirms their quantitative differences in different countries. European legislation defines a prevalence threshold of 1 per 2,000 persons. The United States in 1983 defined the threshold for $\mathrm{RD}$ as $<200,000$ affected people in the country (currently 1 in 1,800 people). Japan considers any disease affecting less than 50,000 people in the country as rare, which is equivalent to less than 1 in 2,500 people. In Russia, one patient per 10,000 people in the population is a sufficient measure for a disease being rare (European Union (EU), 2000; Donnart et al., 2013; Richter et al., 2015; Ferreira, 2019; Wakap et al., 2020). RDs are diagnosed in all fields of medicine and occur in all demographic groups (Pariser and Gahl, 2014). 
There is a variation and steady increase in the reported RDs according to the main available sources. The Online Mendelian Inheritance in Man (OMIM) database contains 6,806 phenotypes with known genetic nature ${ }^{1}$. According to the Orphanet portal of $\mathrm{RDs}$, about 10,500 RDs are currently registered ${ }^{2}$. A very detailed analysis of the known number, point, and cumulative prevalences of RDs has been performed by several teams (Ferreira, 2019; Wakap et al., 2020). Reviews on RD number analysis and point prevalence estimation cite data from the "Epidemiology section of Orphanet". It has been shown that $84.5 \%$ of the analyzed diseases from the Orphanet database have a point prevalence less than 1 per 1,000,000. However, $77.3-80.7 \%$ of the burden of RDs in the population falls on a limited number of diseases, representing only about $4.2 \%$ of all identified diseases, with a point prevalence of one to five per 10,000 of the population (Wakap et al., 2020). Ferreira estimates the burden of RDs with manifestation at different periods of life as $6.2 \%$ of the total population (Ferreira, 2019). A more conservative estimate by Wakap et al. (2020) demonstrates the cumulative prevalence of $\mathrm{RDs}$ in the population to be $3.5-5.9 \%$.

According to various researchers, $72-80 \%$ of RDs have a genetic cause, some of which have already been confirmed (Richter et al., 2015; Wakap et al., 2020). The widespread introduction of technologies of whole genome and/or wholeexome analysis into practical healthcare has significantly increased the number of genetically determined diseases in the structure of human morbidity. While by 2012 the molecular nature was identified for 3,650 nosological forms, there has been a greater increase in genetically determined diseases over the past 5 years. According to annual observations of OMIM statistics in 2016, molecular nature was confirmed for 5,888 diseases, in 2017-6,087 $(+199)$, in 2018-6340 $(+253)$, in $2019-6572(+232)$, and in $2020-6,800(+228)$, i.e., genetic nature is established for an additional 200-250 diseases each year (see text footnote 1). Most of the newly reported forms are rare and found in single families.

Since genetic diseases constitute a high percentage in the $\mathrm{RD}$ group, it is advisable to assess the point prevalence of monogenic hereditary diseases in the modern population based on actual data from a specific population survey. This article provides an epidemiological analysis of the point prevalence of rare monogenic hereditary diseases (RHDs) in geographically remote populations of the European part of Russia.

\section{RESULTS}

The population of 96 rural areas, 86 small towns, and urban-type settlements were surveyed during this study. Data on patients with presumptive RHDs were obtained using a questionnaire (Zinchenko et al., 2020b) from medical workers from 125 medical clinics and 2,056 rural ambulant clinics. More than 45,000 patients with various presumably hereditary conditions,

\footnotetext{
${ }^{1}$ https://omim.org/statistics/geneMap

${ }^{2} \mathrm{http}: / /$ www.orphadata.org/

${ }^{3}$ http://www.orphadata.org/cgi-bin/epidemio.html
}

including patients with structural chromosomal changes, multiple congenital malformations, and isolated anomalies, were examined in total. A total of 554 clinical forms of RHDs were verified in 10,265 patients (including 4,270 children patients).

Table 1 shows the number of identified patients with RHDs in the regions and the variation of the cumulative prevalence for administrative districts within particular regions.

The cumulative prevalence for all RHDs in the sample examined was 277.21 per 100,000 (Zinchenko et al., 2001a,b, 2007, 2009), 558.71 per 100,000 children (Zinchenko et al., 2019, 2020a). The differentiation in the values of cumulative prevalence by region was explained by the peculiarities of the genetic structure of various populations. In the sample under consideration, the main factor of microevolution is genetic drift, migration processes with little influence of natural selection. These results were demonstrated in studies on the role of the genetic structure in the formation of cumulative prevalence in every population (Zinchenko et al., 2000, 2009, 2020b). The number of familial cases averaged $57.82 \%$. There were no statistically significant differences between the cumulative prevalence of $\mathrm{AD}$ and $\mathrm{AR}$ pathology in the groups of men and women $(p>0.05)$.

After that, we have analyzed the point prevalence values and the number of diseases by groups in the surveyed populations (Table 2). The highest number of patients was found in point prevalence class 1 (1:50,000 and more) (59.46\%) with the autosomal dominant $(\mathrm{AD})$ type of inheritance-the autosomal recessive (AR) type of inheritance was observed in $34.66 \%$ of patients, the X-linked (XL) type of inheritance in $7.88 \%$. The

TABLE 1 | Number of identified patients with RHDs and variation of cumulative prevalence for administrative districts within particular regions ( $\mathrm{min} / \mathrm{max}$ ).

\begin{tabular}{|c|c|c|c|}
\hline $\begin{array}{l}\text { Region of the Russian } \\
\text { Federation }\end{array}$ & $\begin{array}{c}\text { Surveyed } \\
\text { population } \\
\text { (number of } \\
\text { districts) }\end{array}$ & $\begin{array}{c}\text { Number of } \\
\text { identified } \\
\text { patients with } \\
\text { RHDs }\end{array}$ & $\begin{array}{c}\text { Variation of } \\
\text { cumulative } \\
\text { prevalence for } \\
\text { districts (min-ma) }\end{array}$ \\
\hline
\end{tabular}

\section{Central part of Russia}

Kostroma region

Kirov region

Bryansk region

Tver region

Republic of Mari El

Chuvash Republic

Republic of Udmurtia

Republic of Tatarstan

Republic of Bashkortostan

Northern part of Russia

Arkhangelsk region

Southern part of Russia and North Caucasus

Krasnodar territory

Rostov region

Republic of Adygea

Republic of

Karachay-Cherkessia

Average

$\begin{array}{ccc}444,476(10) & 673 & 1: 121-1: 545 \\ 286,600(11) & 589 & 1: 83-1: 548 \\ 88,200(1) & 133 & 1: 324-1: 422 \\ 75,000(2) & 131 & 1: 260-1: 405 \\ 276,000(7) & 630 & 1: 78-1: 286 \\ 264,419(6) & 679 & 1: 150-1: 550 \\ 267,655(6) & 794 & 1: 78-1: 375 \\ 264,098(8) & 1516 & 1: 88-1: 350 \\ 250,110(8) & 1192 & 1: 88-1: 389 \\ & & \\ 40,000(5) & 104 & 1: 150-1: 281 \\ \text { North Caucasus } & & \\ 426,600(6) & 740 & 1: 202-1: 556 \\ 497,460(12) & 1481 & 1: 165-1: 340 \\ 112,400(4) & 233 & 1: 236-1: 387 \\ 410,368(10) & 1857 & 1: 85-1: 405\end{array}$

$\mathbf{3 , 7 0 3 , 0 1 8 ( 9 6 ) \quad 1 0 2 6 5}$ 
TABLE 2 | Distribution of patients with AD, AR, and X-linked inheritance patterns of RHDs depending on the point prevalence values and the number of diseases by groups ${ }^{1}$.

\begin{tabular}{|c|c|c|c|c|c|c|c|c|}
\hline \multirow{2}{*}{$\begin{array}{l}\text { Point } \\
\text { prevalence }\end{array}$} & \multicolumn{2}{|c|}{$A D$} & \multicolumn{2}{|c|}{ AR } & \multicolumn{2}{|c|}{$X L$} & \multicolumn{2}{|c|}{ Total } \\
\hline & $\begin{array}{l}\text { Abs. num. } \\
\text { of patients } \\
(\%)\end{array}$ & $\begin{array}{c}\text { Num. of } \\
\text { diseases } \\
(\%)\end{array}$ & $\begin{array}{l}\text { Abs. num. } \\
\text { of patients } \\
(\%)\end{array}$ & $\begin{array}{c}\text { Num. of } \\
\text { diseases } \\
(\%)\end{array}$ & $\begin{array}{l}\text { Abs. num. } \\
\text { of patients } \\
(\%)\end{array}$ & $\begin{array}{c}\text { Num. of } \\
\text { diseases } \\
(\%)\end{array}$ & $\begin{array}{l}\text { Abs. num. } \\
\text { of patients } \\
(\%)\end{array}$ & $\begin{array}{c}\text { Num. of } \\
\text { diseases } \\
(\%)\end{array}$ \\
\hline $\begin{array}{l}1: 50,000 \text { and } \\
\text { more }\end{array}$ & $\begin{array}{c}3,358 \\
(56.93 \%)\end{array}$ & $\begin{array}{c}17 \\
(6.39 \%)\end{array}$ & $\begin{array}{c}2,253 \\
(63.32 \%)\end{array}$ & $\begin{array}{c}11 \\
(4.80 \%)\end{array}$ & $\begin{array}{c}534 \\
(66.01 \%)\end{array}$ & $\begin{array}{c}5 \\
(8.47 \%)\end{array}$ & $\begin{array}{c}6,145 \\
(59.86 \%)\end{array}$ & $\begin{array}{c}33 \\
(5.96 \%)\end{array}$ \\
\hline $\begin{array}{l}1: 50,001- \\
1: 100,000\end{array}$ & $\begin{array}{c}742 \\
(12.58 \%)\end{array}$ & $\begin{array}{c}16 \\
(6.02 \%)\end{array}$ & $\begin{array}{c}205 \\
(5.76 \%)\end{array}$ & $\begin{array}{c}5 \\
(2.18 \%)\end{array}$ & $\begin{array}{c}76 \\
(9.39 \%)\end{array}$ & $\begin{array}{c}3 \\
(5.08 \%)\end{array}$ & $\begin{array}{c}1023 \\
(9.97 \%)\end{array}$ & $\begin{array}{c}24 \\
(4.33 \%)\end{array}$ \\
\hline $\begin{array}{l}1: 100,001- \\
1: 200,000\end{array}$ & $\begin{array}{c}643 \\
(10.90 \%)\end{array}$ & $\begin{array}{c}26 \\
(9.77 \%)\end{array}$ & $\begin{array}{c}363 \\
(10.20 \%)\end{array}$ & $\begin{array}{c}10 \\
(4.37 \%)\end{array}$ & $\begin{array}{c}72 \\
(8.90 \%)\end{array}$ & $\begin{array}{c}6 \\
(10.17 \%)\end{array}$ & $\begin{array}{c}1,078 \\
(10.50 \%)\end{array}$ & $\begin{array}{c}42 \\
(7.58 \%)\end{array}$ \\
\hline $\begin{array}{l}1: 200,001- \\
1: 300,000\end{array}$ & $\begin{array}{c}481 \\
(8.16 \%)\end{array}$ & $\begin{array}{c}34 \\
(12.78 \%)\end{array}$ & $\begin{array}{c}193 \\
(5.42 \%)\end{array}$ & $\begin{array}{c}14 \\
(6.11 \%)\end{array}$ & $\begin{array}{c}43 \\
(5.32 \%)\end{array}$ & $\begin{array}{c}6 \\
(10.17 \%)\end{array}$ & $\begin{array}{c}717 \\
(6.98 \%)\end{array}$ & $\begin{array}{c}54 \\
(9.75 \%)\end{array}$ \\
\hline $\begin{array}{l}1: 300,001- \\
1: 400,001\end{array}$ & $\begin{array}{c}214 \\
(3.63 \%)\end{array}$ & $\begin{array}{c}22 \\
(8.27 \%)\end{array}$ & $\begin{array}{c}110 \\
(3.09 \%)\end{array}$ & $\begin{array}{c}11 \\
(4.80 \%)\end{array}$ & $\begin{array}{c}10 \\
(1.24 \%)\end{array}$ & $\begin{array}{c}2 \\
(3.39 \%)\end{array}$ & $\begin{array}{c}334 \\
(3.25 \%)\end{array}$ & $\begin{array}{c}35 \\
(6.32 \%)\end{array}$ \\
\hline $\begin{array}{l}1: 400,001- \\
1: 500,002\end{array}$ & $\begin{array}{c}56 \\
(0.95 \%)\end{array}$ & $\begin{array}{c}7 \\
(2.63 \%)\end{array}$ & $\begin{array}{c}64 \\
(1.80 \%)\end{array}$ & $\begin{array}{c}8 \\
(3.49 \%)\end{array}$ & $\begin{array}{c}4 \\
(0.49 \%)\end{array}$ & $\begin{array}{c}1 \\
(1.69 \%)\end{array}$ & $\begin{array}{c}124 \\
(1.21 \%)\end{array}$ & $\begin{array}{c}16 \\
(2.89 \%)\end{array}$ \\
\hline $\begin{array}{l}1: 500,001 \text { and } \\
\text { less }\end{array}$ & $\begin{array}{c}404 \\
(6.85 \%)\end{array}$ & $\begin{array}{c}144 \\
(54.14 \%)\end{array}$ & $\begin{array}{c}370 \\
(10.40 \%)\end{array}$ & $\begin{array}{c}170 \\
(74.24 \%)\end{array}$ & $\begin{array}{c}70 \\
(8.65 \%)\end{array}$ & $\begin{array}{c}36 \\
(61.02 \%)\end{array}$ & $\begin{array}{c}844 \\
(8.22 \%)\end{array}$ & $\begin{array}{c}350 \\
(63.18 \%)\end{array}$ \\
\hline Total & 5,898 & 266 & 3,558 & 229 & 809 & 59 & 10,265 & 554 \\
\hline
\end{tabular}

${ }^{1}$ OMIM-Online Mendelian Inheritance in Man; PS-Phenotypic Series for OMIM with heterogeneity of the disease; AD-autosomal dominant type of inheritance; ARautosomal recessive type of inheritance; XL-X-linked type of inheritance. Point prevalence for X-linked pathology is for 100,000 of the male population.

same ratio is observed in the analysis of the number of detected diseases: with the $\mathrm{AD}$ type of inheritance-48.01\%; with $\mathrm{AR}-$ $41.34 \%$; and with XL-10.65\%. Analysis of the distribution of the number of patients according to the point prevalence values showed that 33 diseases accounted for most of the patients (59.86\%), representing only $5.96 \%$ of the total number of diseases (Figure 1). The class of RHDs with a point prevalence of "1:500,001 and less" represents 350 diseases $(63.18 \%$ of all detected RHDs) with 844 patients ( $8.22 \%$ of the patients): $6.85 \%$ with the AD type of inheritance, $10.40 \%$ with the AR type, and $8.65 \%$ with the XL type.

Next, we have analyzed reported diseases and the number of patients with a point prevalence of 1:100,000 or more (Table 3). Table 3 also presents disease prevalence values (adjusted for gender differences) and point prevalence in the child population. It is worth noting that for congenital diseases and those with manifestation in childhood, the prevalence in the child population is much higher than in the general population. Most of the diseases are from heterogeneous groups but having a similar clinical picture. For example, about 100 genetic forms with similar clinical manifestations of the disease are known for retinitis pigmentosa. In our studies, we also determined a wide heterogeneity for this disease based on NGS studies-we diagnosed 35 clinical genetic variants, and they are combined under the clinical diagnosis "retinitis pigmentosa" in Table 3. Some forms were listed separately, i.e., Stargardt disease, because it has characteristic features and is well diagnosed clinically. The same pattern is observed for Charcot-Marie-Tooth disease, the verification of specific nosological forms in most cases being determined by a molecular genetic study. RHDs vary in prevalence, locus, and allelic heterogeneity depending on the geographic region, which is associated with the specific genetic structure of the population. More than 20 rare genetic variants for Charcot-Marie-Tooth disease associated with different loci and represented by single families have been identified in different regions of Russia (Schagina et al., 2007; Khidiyatova et al., 2013; Dadali et al., 2016; Shchagina et al., 2018, 2020; Murtazina et al., 2020).

Differential diagnosis of "undifferentiated intellectual disability" is particularly difficult, and work is being done in this direction identifying new genes and genetic variants, most of which we identify in single families (Levchenko et al., 2019). In our sample, the majority of cases were familial.

In Russia, we have identified allelic heterogeneity, and regional and ethnic peculiarities, for most diseases included in newborn screening (Petrova et al., 2016, 2019a,b; Gundorova et al., 2018). Our studies identified the highest prevalence of phenylketonuria around the world (birth prevalence 1:850 newborns) in one region of the Russian Federation, and it is associated with the spread of a specific mutation (p.R261* in the PAH gene) associated with the founder effect (Gundorova et al., 2018). The study of allelic heterogeneity is necessary because the varying significance of different genetic variants leads to different clinical courses of diseases and treatment correction (Petrova et al., 2016, 2019a,b; Gundorova et al., 2018). For some diseases, the analysis of genotype-phenotype correlations and the mutation spectrum has identified peculiarities of the clinical course of the disease (Andreeva et al., 2016; Marakhonov et al., 2019; Petrova et al., 2019b; Vasilyeva et al., 2021).

In addition to RHDs that are frequent for all populations of the Russian Federation and Europe, regionally specific diseases have been identified. Our study identified diseases endemic to specific regions of the Russian Federation-several 


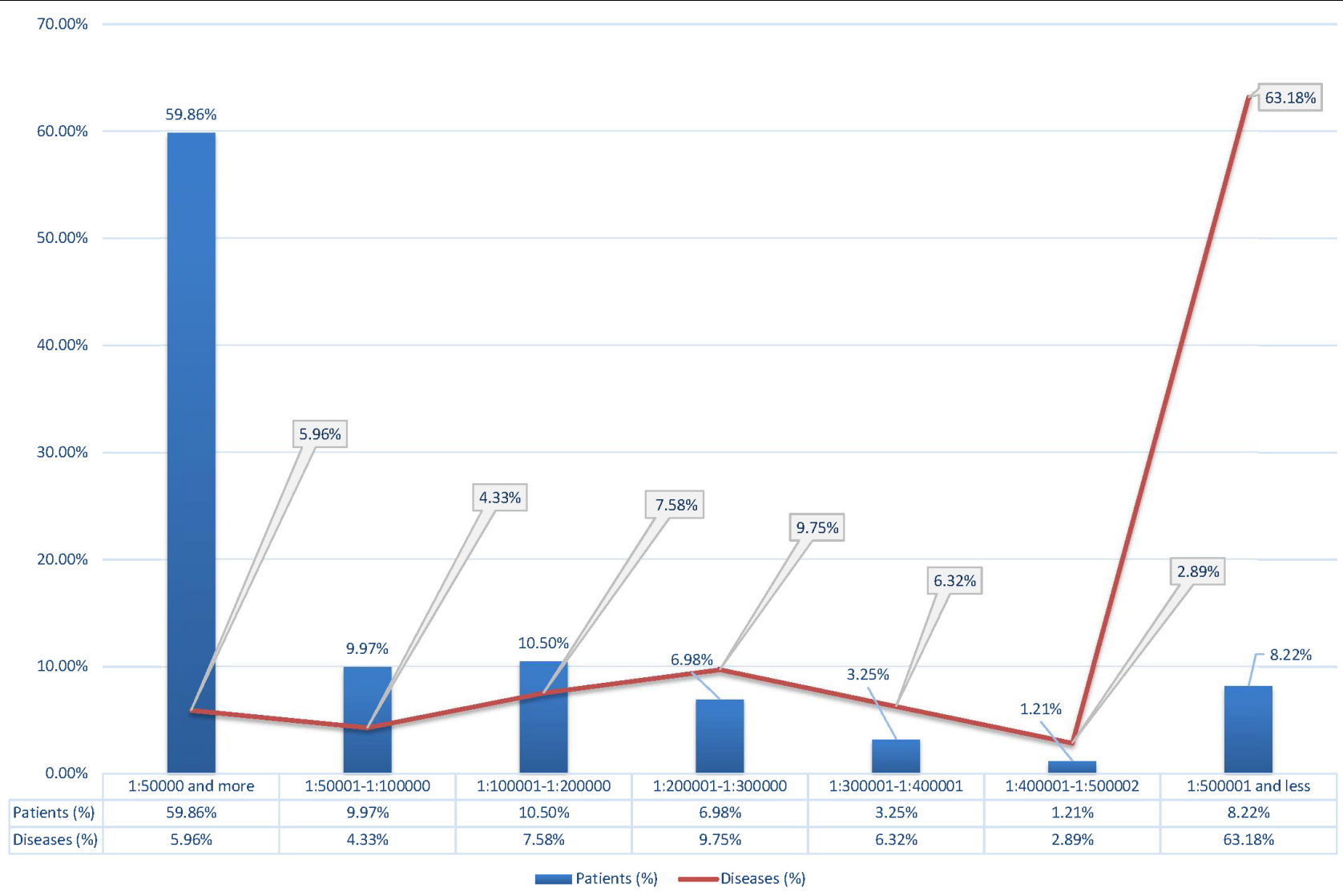

FIGURE 1 | Percentage of patients and diseases according to the point prevalence values.

types of hypotrichosis (Kazantseva et al., 2006; Zernov et al., 2016), osteopetrosis (Bliznetz et al., 2009), and a number of RDs identified in the Russian Federation and worldwide in single cases-primary microcephaly (Marakhonov et al., 2018), gnathodiaphyseal dysplasia (Andreeva et al., 2016), metatropic dysplasia (Timkovskaya et al., 2016), etc.

The assessment of the cumulative prevalence and burden of RHDs according to the common medical classification of diseases is important for public health and public policy in Russia and in European countries.

We analyzed the diversity and point prevalence of RHDs according to the conventional classification of the disease by types of affected organs and systems according to their main clinical manifestations-neurological syndrome, ophthalmic syndrome, genodermatoses, skeletal syndrome, hereditary syndrome, and other pathology (hereditary diseases of metabolism, blood, hearing, etc.). Table 3 presents the number of patients, the number of diseases, and the point prevalence of RHDs distributed according to the medical classification of diseases.

Analysis of Table 4 shows that the maximum number of patients (23.56\%) was found to have neurological and psychiatric pathology, the cumulative point prevalence of which is $65.30 / 100,000$ or $1: 1530$ people. The next most numerous groups were hereditary syndromes-18.04\% (cumulative point prevalence $50.01 / 100,000$ or $1: 2,000$ ) and other pathology (hereditary diseases of metabolism, blood, hearing, etc.) $-17.11 \%$ (47.42/100,000 or 1:2,109 people). For the first two groups of diseases, the maximum incidence was 18.38 and $36.94 \%$, respectively.

Analysis of the age category of patients with RHDs showed that the majority of patients (about $45.3 \%$ ) belonged to the category of childhood (from newborn to 17 full years), despite the fact that the share of the child population in the regions is only $20.64 \%$; for the reproductive and post-reproductive age, $54.7 \%$ of all patients. The results obtained demonstrate the need to develop preventive programs specifically among children.

\section{DISCUSSION}

The issue of point prevalence, cumulative prevalence, and burden of RHDs is discussed in many articles and is an urgent problem that is associated with the rapid progress of genetic technology, the identification of thousands of genes, and the problems in society, public health, and social structures of states. According to OMIM statistics, genetic nature has been determined for 6,806 phenotypes so far, and the genetic nature is established for another 200-250 diseases each year (see text footnote 1). Current medical classifications have not kept pace with genetic progress; nosological forms of RHDs are underrepresented in 
TABLE 3 | Reported diseases with high point prevalence of 1:100,000 or more and the number of patients (ranging in decreasing number of total point prevalence).

\begin{tabular}{|c|c|c|c|c|}
\hline OMIM \# & Diagnosis & $\begin{array}{c}\text { Number of } \\
\text { patients }\end{array}$ & $\begin{array}{l}\text { Point prevalence per } \\
100,000 \text { (including } \\
\text { men/women) }\end{array}$ & $\begin{array}{c}\text { Point prevalence per } 100,000 \\
\text { children (newborn-17 years } \\
\text { old/boys*) }\end{array}$ \\
\hline
\end{tabular}

\section{Autosomal dominant RHDs}

\section{Point prevalence 1:50,000 and more}

\begin{tabular}{|c|c|c|c|c|}
\hline \#146700 & Ichthyosis vulgaris & 646 & $17.45(8.61 ; 8.83)$ & 34.15 \\
\hline PS130000 & Ehlers-Danlos syndrome & 459 & $12.40(6.13 ; 6.27)$ & 28.00 \\
\hline \#148700 & Keratosis palmoplantaris & 304 & $8.21(3.81 ; 4.40)$ & 14.52 \\
\hline PS118220 & Charcot-Marie-Tooth disease & 232 & $6.27(3.02 ; 3.24)$ & 5.23 \\
\hline PS116200 & Congenital hereditary cataract & 215 & $5.81(2.89 ; 2.92)$ & 15.05 \\
\hline \#162200 & Neurofibromatosis, type I & 199 & $5.37(2.67 ; 2.70)$ & 10.60 \\
\hline PS156200 & Undifferentiated intellectual disability & 177 & $4.78(2.40 ; 2.38)$ & 9.42 \\
\hline \#146000 & Hypochondroplasia & 164 & $4.43(2.08 ; 2.35)$ & 3.14 \\
\hline PS124900 & Deafness, autosomal dominant & 133 & $3.59(1.50 ; 2.09)$ & 3.14 \\
\hline 178300 & Ptosis, hereditary congenital & 126 & $3.40(1.76 ; 1.65)$ & 12.04 \\
\hline PS268000 & Retinitis pigmentosa & 122 & $3.29(1.62 ; 1.67)$ & 4.97 \\
\hline PS174200 & Polydactyly, postaxial, type A1 & 112 & $3.02(1.57 ; 1.46)$ & 8.50 \\
\hline 151900 & Lipomatosis, multiple & 108 & $2.92(1.38 ; 1.54)$ & 0 \\
\hline \#154700 & Marfan syndrome & 105 & $2.84(1.40 ; 1.48)$ & 8.23 \\
\hline PS166200 & Osteogenesis imperfecta & 100 & $2.70(1.32 ; 1.38)$ & 7.98 \\
\hline \#185900 & Syndactyly, type I & 84 & 2.27 (1.08; 1.19) & 7.46 \\
\hline PS163950 & Noonan syndrome 1 & 72 & $2.03(0.85 ; 1.12)$ & 5.40 \\
\hline
\end{tabular}

\section{Point prevalence 1:500,01-1:100,000}

\begin{tabular}{lcccc}
\hline$\# 160900$ & Dystrophia myotonica 1 & 65 & $1.76(0.80 ; 0.95)$ & 1.05 \\
181800 & Scoliosis, idiopathic & 69 & $1.86(0.86 ; 1.00)$ & 5.10 \\
$\# 133700$ & Exostoses, multiple, type I & 56 & $1.51(0.81 ; 0.70)$ & 4.19 \\
$\# 100800$ & Achondroplasia & 54 & $1.46(0.70 ; 076)$ & 0 \\
$\# 143100$ & Huntington disease & 51 & $1.38(0.65 ; 0.73)$ & 4.19 \\
$\# 120200$ & Coloboma, ocular & 49 & $1.32(0.48 ; 0.85)$ & 4.58 \\
PS310700 & Nystagmus, congenital & 49 & $1.32(0.53 ; 0.80)$ & 3.79 \\
PS183600 & Split-hand/foot malformation 1 & 45 & $1.22(0.23 ; 0.22)$ & 3.27 \\
PS174400 & Polydactyly, preaxial I & $1.19(0.57 ; 0.62)$ & 1.57 \\
PS303350 & Spastic paraplegia, autosomal dominant & 44 & $1.13(0.59 ; 0.54)$ & \\
$\# 110100$ & Blepharophimosis, ptosis & 42 & $1.11(0.57 ; 0.54)$ & 1.83 \\
126070 & Albinoidism, oculocutaneous, autosomal dominant & 41 & $1.05(0.51 ; 0.54)$ & 0.92 \\
$\# 158900$ & Facioscapulohumeral muscular dystrophy 1A & 39 & $1.05(0.49 ; 0.57)$ & 0.79 \\
PS165500 & Optic atrophy 1 & 39 & $1.03(0.57 ; 0.46)$ & 1.44 \\
$\# 186000$ & Synpolydactyly 1 & 38 & $1.00(0.46 ; 0.54)$ & 2.75 \\
$\# 106210$ & Aniridia & 37 & $1.00(0.49 ; 0.51)$ & 3.27 \\
\hline
\end{tabular}

\section{Autosomal recessive RHDs}

\section{Point prevalence 1:50,000 and more}

\begin{tabular}{lcccc}
\hline PS220290 & Deafness, autosomal recessive & 776 & $20,96(9.91 ; 11.05)$ & 59.27 \\
PS249500 & Undifferentiated intellectual disability & 431 & $11.64(5.40 ; 6.24)$ & 29.31 \\
PS251200 & Microcephaly, primary autosomal recessive & 155 & $4.19(2.11 ; 2.08)$ & 17.14 \\
PS268000 & Retinitis pigmentosa & 150 & $4.05(1.92 ; 2.13)$ & 2.88 \\
$\# 261600$ & Phenylketonuria & 145 & $3.92(2.00 ; 1.92)$ & 15.05 \\
PS116200 & Congenital hereditary cataract & 105 & $2.84(1.40 ; 1.43)$ & 8.24 \\
$\# 242100$ & Ichthyosiform erythroderma, congenital & 84 & $2.27(1.08 ; 1.19)$ & 5.23 \\
PS253600 & Muscular dystrophy, limb-girdle & 83 & $2.24(1.11 ; 1.13)$ & 1.70 \\
PS203100 & Albinism, oculocutaneous & 81 & $2.19(1.05 ; 1.13)$ & 7.85 \\
$\# 253300$ & Spinal muscular atrophy, types I-III & 72 & $2.03(1.01 ; 1.01)$ & 8.23
\end{tabular}


TABLE 3 | Continued

\begin{tabular}{|c|c|c|c|c|}
\hline OMIM \# & Diagnosis & $\begin{array}{c}\text { Number of } \\
\text { patients }\end{array}$ & $\begin{array}{l}\text { Point prevalence per } \\
100,000 \text { (including } \\
\text { men/women) }\end{array}$ & $\begin{array}{c}\text { Point prevalence per } 100,000 \\
\text { children (newborn-17 years } \\
\left.\text { old/boys }{ }^{*}\right)\end{array}$ \\
\hline PS262400 & Growth hormone deficiency & 72 & $2.03(1.02 ; 1.00)$ & 1.70 \\
\hline \multicolumn{5}{|c|}{ Point prevalence 1:50,001-1:100,000 } \\
\hline PS276900 & Usher syndrome & 52 & $1.40(0.68 ; 0.73)$ & 2.36 \\
\hline PS204000 & Leber congenital amaurosis & 44 & $1.19(0.50 ; 0.66)$ & 1.44 \\
\hline \#248200 & Stargardt disease 1 & 43 & $1.16(0.62 ; 0.57)$ & 1.83 \\
\hline \#604379 & Hypotrichosis, total, Mari type & 39 & $1.05(0.52 ; 0.53)$ & 1.75 \\
\hline \#219700 & Cystic fibrosis & 37 & $1.00(0.49 ; 0.51)$ & 4.45 \\
\hline
\end{tabular}

\section{X-linked RHDs}

\section{Point prevalence 1:50,000 and more}

\begin{tabular}{|c|c|c|c|c|}
\hline PS309530 & Undifferentiated intellectual disability, X-linked & 226 & $12.21(12.21 ; 0)$ & $30.09^{\star}$ \\
\hline \#308100 & Ichthyosis, X-linked & 124 & $6.70(6.70 ; 0)$ & $15.70^{\star}$ \\
\hline \#306700 & Hemophilia A & 78 & $4.21(4.21 ; 0)$ & $12.04^{\star}$ \\
\hline \#310200 & Muscular dystrophy, Duchenne type & 55 & $2.97(2.97 ; 0)$ & $10.21^{*}$ \\
\hline PS310700 & Nystagmus, congenital, X-linked & 51 & $2.75(2.75 ; 0)$ & $11.51^{*}$ \\
\hline \multicolumn{5}{|c|}{ Point prevalence 1:50,001-1:100,000 } \\
\hline \#305400 & Faciogenital dysplasia & 32 & $1.73(1.67 ; 0)$ & $7.59^{\star}$ \\
\hline \#300376 & Muscular dystrophy, Becker type & 24 & $1.30(1.30 ; 0)$ & $1.24^{*}$ \\
\hline \#302800 & Charcot-Marie-Tooth disease, X-linked dominant & 20 & $1.08(0.53 ; 0.55)$ & 4.71 \\
\hline
\end{tabular}

*Point prevalence for X-linked pathology is estimated for 100,000 boys.

TABLE 4 | Structure of the diversity and point prevalence of the RHDs in accordance with the main medical classification of diseases.

Types of the hereditary disease

\begin{tabular}{llc}
\cline { 2 - 3 } & $\begin{array}{c}\text { Abs. num. of } \\
\text { patients (\%) }\end{array}$ & $\begin{array}{c}\text { Point prevalence } \\
\text { per 100,000 }\end{array}$ \\
\hline Neurological and psychiatric & $2418(23.56 \%)$ & 65.30 \\
Ophthalmic & $1524(14.85 \%)$ & 41.16 \\
Genodermatoses & $1510(14.71 \%)$ & 40.78 \\
Skeletal & $1205(11.74 \%)$ & 32.54 \\
Hereditary syndromes & $1852(18.04 \%)$ & 50.01 \\
Other pathology (hereditary diseases of & $1756(17.11 \%)$ & 47.42
\end{tabular}

Patient data

Disease data

metabolism, blood, hearing, etc.)

coding systems (e.g., International Classification of Disease, ICD-11). Data collection from different researchers lacks a unified methodological approach, which makes comparative analysis difficult. Insufficient organization of the process, lack of knowledge, lack of diagnostic expertise, lack of information on point prevalence, distribution of RHDs by medical areas, and cumulative burden of RHDs prevent the full development of a public health strategy. In addition to public health questions, it is a priority to provide medical care for patients with specific RHDs and to identify the most common RHDs for the necessary prioritization and development of regional, national, and global health programs.

This study presents an epidemiological analysis of the point prevalence of RHDs based on actual material based on a total survey of several regions of the European part of Russia. Russia is a multinational country with a population of $146,238,185$, which makes it difficult to choose a unified strategy in public health. Fourteen regions (Northern, Central, and Southern Russia) were chosen for the survey and subsequent analysis, both populations with different ethnic extractions, and regions of a single ethnic origin. Selection of different ethnically diverse territories in a multinational country was necessary to be able to identify groups of the most common RHDs, determine point prevalence, and describe the structure of RHDs diversity by medical areas. The study was performed by a single team, and the collection and processing of material remained unchanged throughout the study.

Despite the listed limitations of the method (see section "Features and Limitations of the Method") in our study, every 351 people have a hereditary disease. Remarkably higher 
values of cumulative prevalence were obtained in childrenthe proportion of children out of the total number of patients with RHDs was $43.3 \%$. This number is remarkably higher than the proportion of children in the general population (20.64\%). The main reason for this age distribution is that up to $70 \%$ of RHDs manifest in childhood according to the Orphanet database. However, the distribution according to the inheritance type was uneven: $39.17 \%$ with $\mathrm{AD}$ pathology, $45.24 \%$ with AR and 52.28\% X-linked. Moreover, the proportion of child patients (of pre-productive age) varied from 38 to $51 \%$ in different surveyed populations (Zinchenko et al., 2019, 2020a). The proportion of patients in the reproductive age (18-45 years) out of the total number of patients with RHDs was $37.2 \%$ (from 31.91 to $40 \%$ by population); for the post-reproductive age (46 and older), only $17.5 \%$ (variation $17-22 \%$ ) out of all patients (Elchinova et al., 2017). Analysis of the sample showed that some diseases do not occur in older age groups because they have high mortality in childhood and middle age (the rate is not constant and varies depending on the population, the causing gene, and the mutation). The lower point prevalence in the older age group is mostly due to a milder and stable course of a limited number of RHDs, with fitting approaching 1 , which reduces their relevance and referral to medical facilities.

The number of familial cases and individual cases in family (including sporadic cases for $\mathrm{AD}$ pathology) varied depending on the type of inheritance and the average size of the family in a particular region. Among families with the $\mathrm{AD}$ type of inheritance, the familial case rate ranged from 70 to $80 \%$ in different populations. In families with the AR type, familial cases were $26-34 \%$; for those X-linked, $15-20 \%$. The distribution of men and women did not differ for autosomal pathology. We assume that due to the limitations detailed in the materials and methods, the data obtained may be an underestimate. However, it should be noted that there was a variation by region and by location. The cumulative prevalence and diversity of RHDs was determined for each region, and the most common RHDs were identified. A general disease registry was then compiled. The analysis showed that a single class of the most common RHDs was identified for all populations, with insignificant variation by region for most diseases. The most significant differences in prevalence were found among the child population for congenital and hereditary diseases with early onset. The largest number of patients was detected in the point prevalence class "1:50,000 and more" -33 clinical forms of RHDs $(5.96 \%$ of the total number of detected diseases) accounting for $59.86 \%$ of the patients. Most of the diseases are from heterogeneous groups of RHDs, and there is locus and allelic heterogeneity by region. The smallest number of patients, $8.22 \%$, was identified in the class of RHDs with a point prevalence of " $1: 500,001$ or less" -350 diseases $(63.18 \%$ of all identified RHDs). These RHDs were mostly detected in single families.

Similar data were obtained by Wakap et al. (2020) when analyzing the Orphanet database epidemiological data (see text footnote 3 ) for RDs, not all of which are of monogenic nature, but only some of them (70-80\%) (Wakap et al., 2020). Their study showed that out of 5,304 diseases-84.5\% have a point prevalence $<1 / 1,000,000$, and $77.3-80.7 \%$ of the burden of RDs in the population accounts for $4.2 \%(n=149)$ of the diseases. The analysis performed in our study on a real contemporary population demonstrates the rarity of most RHDs affecting single families and highlights the difficulty of detection and diagnosis by physicians.

Wakap et al. (2020) also highlighted that it would be a benefit to perform an analysis of distribution of diseases in real populations according to the medical classification for organization of real medical care. An analysis of the pattern of diversity of RHDs by medical specialties, which has been performed in the current study, showed a predominance of patients (41.60\% of patients) with neurological, psychiatric, and hereditary syndromes with a point prevalence of 115/100,000 people. Most diseases of neurological, psychiatric, and hereditary syndromes; hereditary metabolism diseases; and hereditary blood diseases are characterized by reduced fitness, multisystemic lesions, disability, and reduced life expectancy and quality because of the lack of effective treatment. Most hereditary skin, eye, ear, skeletal, and treatable metabolic diseases could affect quality of life (including possible disability) but have adaptation in society and average life expectancy. The findings require a comprehensive public health approach.

\section{CONCLUSION}

In conclusion, the present time is characterized by the accumulation of data on the point prevalence of RHDs, and this will help to systematize our knowledge and allow us to develop a strategy of healthcare for patients with RHDs.

\section{MATERIALS AND METHODS}

We analyzed long-term studies (1985-2020) on the epidemiology of rare monogenic hereditary diseases in the European part of Russia. This approach allows us to identify disease peculiarities in a given region and provides insight into the diversity of rare hereditary pathologies and their point prevalence.

\section{Surveyed Population}

Russia is a multinational state with more than 190 ethnic groups, with Russians constituting about $80 \%$. The study covered various remote areas of European Russia-Central, Northern, Southern, and the North Caucasus. The relative location of the studied regions is shown in Figure 2. The selection of survey areas in each region was focused on the indigenous population (the history and migration flows of population formation were studied). Table 5 shows the populations surveyed, the size of child populations, the ethnic composition of the populations, number of medical organizations (hospital, medical ambulance, paramedic, and obstetric centers), and the number medical workers (physicians, nurses, paramedics) participated in the study. The total size of the surveyed population was $3,703,018$ people from 96 rural districts, including 764,260 children (from newborns to 17 full years of age). The sex distribution of the 


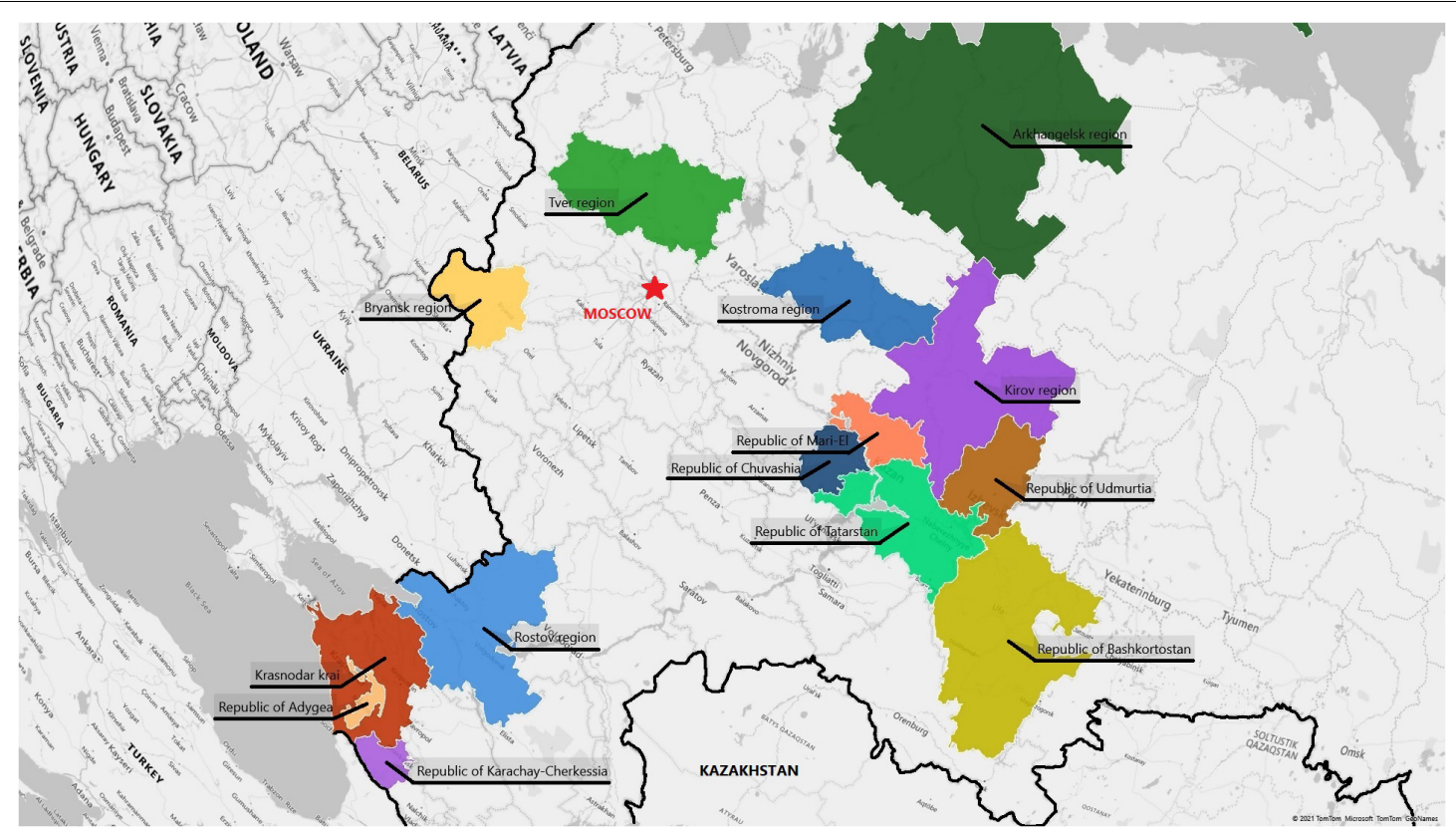

FIGURE 2 | Map of Russian Federation with regions included into the study. The border of the Russia is in bold.

total surveyed population was 1,716,298 (46.35\%) men/1,987,087 (53.66\%) women ${ }^{4}$. There was an uneven distribution in age: up to 35 years 1:1 (M/W), 36-50 years 0.8:1 (M/W), and the postreproductive period $0.6: 1(\mathrm{M} / \mathrm{W})$. In total, from the surveyed regions, the study involved 2,181 medical organization and 6,370 medical workers. Each of the studied districts of the particular region has one central district hospital, which includes inpatient and medical ambulance, and several rural ambulances and paramedic-obstetric centers in the villages. The number of rural medical organizations depends on the number of villages in the region and is determined by the Department of Medical Statistics of the hospital. The medical workers permanently residing in the area has full medical information about the attached population.

\section{Survey and Protocol}

The survey was carried out by a single team of the Research Centre for Medical Genetics (RCMG) in accordance with the protocol of medical and genetic examination of small populations described previously in detail (Zinchenko et al., 2020b). A survey of the investigated populations was conducted regardless of ethnicity, age, and gender structure. The protocol includes the study of populations through different genetic systems simultaneously: (1) population survey, study of the point and cumulative prevalence of hereditary diseases in the particular population; (2) study of the genetic structure using standard methods of population statistics (analysis of the marriages and migration structure, demographic data, analysis of the frequency of surnames to obtain indicators of random inbreeding through

${ }^{4}$ https://infotables.ru/statistika/31-rossijskaya-federatsiya/200-sootnosheniechislennosti-muzhchin-i-zhenshchin-rossii-v-2010-i-2002-godakh-tablitsa isonymy); and (3) study of the genetic structure through the neutral DNA loci of the nuclear genome.

The survey was conducted in three consecutive steps in accordance with the protocol. At the first step, a lecture course is conducted for all medical workers of each surveyed districts of regions (physicians of different specialties, nurses, paramedics) to explain the goals and objectives of the study. During the lecture, the medical personnel are given an information card-questionnaire (Figure 3A) with request for filling in the information on patients (Figure 3B), including those at the initial stage of disease and with minimal clinical manifestations $s^{5}$. The questionnaire contains easily detectable clinical symptoms of RHDs, almost each of which is characteristic for a group of diseases (isolated, syndromic forms). This protocol allowed the detection of the maximum possible number of nosological forms of RHDs known to date. The card-questionnaire with the listed symptoms allows to reveal practically all "portrait" syndromes. Registration of families presumably with RHDs was done through affected persons in the family. The "Multiple registration" method was used (Cavalli-Sforza and Bodmer, 1999). In addition to the questionnaire card, other sources of information are involved: (i) data on disabled persons (from childhood to adults) in the district provided by the hospital; (ii) information from special schools for the blind and visually impaired, deaf, and hard

${ }^{5}$ Transfer of patients' data was performed in accordance with Article 13 of Federal Law No. 323-FL "On the basics of health protection of citizens of the Russian Federation" which allowed the submission of information about patients in the following cases: the exchange of information by medical organizations, including those deposited in medical information systems, for the purpose of providing medical care, taking into account the requirements of the legislation of the Russian Federation (paragraph 8), as well as for the purpose of accounting and control within the mandatory medical insurance system (paragraph 9) [http://docs.cntd. $\mathrm{ru} /$ document/902312609]. 
TABLE 5 | Number, ethnic composition of the surveyed populations, number of organization, and medical workers who participated in the study.

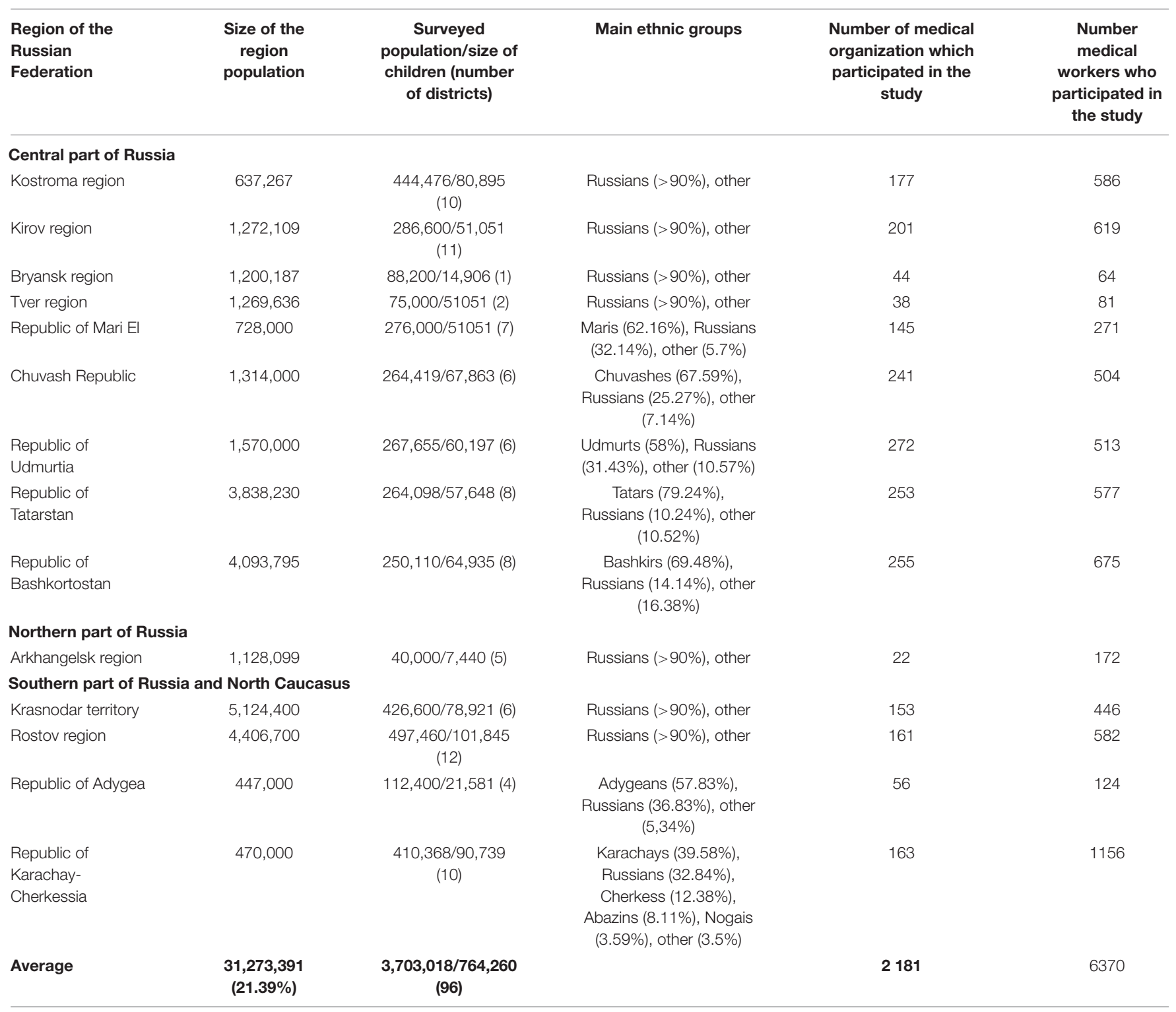

of hearing and schools for children with intellectual disability; and (iii) data from the genetic counseling unit. Thus, registration of the same patient was possible from several sources of information, i.e., being multiple, but recorded in a single database as one case for further examination. A one-time examination of congenital and hereditary pathology in each region is carried out. In the aggregate, the detection rate of patients from all sources of registration reaches $80 \%$.

At the second step, the patients were examined by clinical geneticists from the RCMG. The patient with the presumed RHDs is given a medical card, which contains personal information of the proband and his family members, a brief medical history, genealogical data, and detailed phenotyping data. In the process of data collection, pedigrees and the possibility of consanguinity were analyzed. Consanguinity was revealed in rare cases. If necessary, a cytogenetic study is conducted to rule out chromosomal abnormalities. In complicated cases, additional examinations were prescribed for patients to be able to verify the diagnoses (biochemical, radiological, electromyographic, and other methods). As a result of this step, a significant proportion of patients (usually, more than half) from different sources is excluded from the sample because of the external cause of the disease (injuries, infections, isolated congenital pathology, etc.). The remainder families represent a list of families presumably with RHDs for further research.

At the third step, clinical investigations were performed by specialists from leading federal research institutes (geneticist, neurologist, ophthalmologist, dermatologist, pediatrician, otolaryngologist, and orthopedist), which ensured unification of diagnostic criteria. In some cases, blood is collected from patients for molecular genetic diagnosis. Written informed consent was obtained from all identified and examined families for voluntary participation in the study. From 1 to $5 \%$ of patients refuse to be 
A

Dear Colleague!

INFORMATION CARD

The Research Center for Medical Genetics performs now an epidemiological study of hereditary disorders in your

District. Here are some symptoms of hereditary disorders:

- hypotonia or hypertonia and seizures of newborns;

- high degree of mental retardation;

- congenital deafness, deaf-mutism;

- blindness, microphthalmia, congenital cataract, congenital glaucoma, coloboma, aniridia, nystagmus, ptosis of eyelids, constriction of visual fields and night blindness;

- short stature, congenital limb deformities and reduction, vertebral defects, cranium and thorax anomalies, peculiar faces, cleft lip with or without cleft palate, polydactyly, syndactyly, combinations of different skeletal anomalies, joints dislocation;

- muscular atrophy or hypertrophy, joint limitation or /and contractures, muscular weakness, palsies, seizures, disturbances of gate, ataxia;

- altered skin pigmentation, thick or ichthyosis skin, hyperkeratosis palmar and plantar, hemangiomata and telangiectasia, multiple skin tumors, loose, redundant skin, epidermolysis, nail hypoplasia or dysplasia, alopecia, anodontia or hypodontia;

- congenital cardiac anomalies combined with other congenital anomalies;

- bleeding disorders;

- hypogonadism, cryptorchidism, hypospadias.

We ask you to present data on the patients with these symptoms living in your district to local hospital. If there is more than one patient in the family, please show this in your card. Please show the first and second name of the patient's parents.

\section{Yours sincerely}

B

District The name of the doctor (paramedic)

Rural outpatient clinic Village

DATA ON PATIENTS WITH A HEREDITARY DISEASES

\begin{tabular}{|l|l|l|l|}
\hline $\begin{array}{c}\text { The name of the } \\
\text { patient }\end{array}$ & Data of birth & Address & $\begin{array}{c}\text { Signs of disease } \\
\text { (symptoms) }\end{array}$ \\
\hline & & & \\
\hline & & & \\
\hline & & & \\
\hline
\end{tabular}

FIGURE 3 | Information card. Front (A) and reverse (B) sides.

examined for various reasons. The study was approved by the Ethical Committee of the Research Centre for Medical Genetics (Protocol No. 17/2006 dated 02.02.2006).

\section{Statistical Methods}

Given the heterogeneity of many diseases, the type of inheritance was also confirmed by segregation analysis used in multiple-family registration (Cavalli-Sforza and Bodmer, 1999). Segregation frequency is calculated by Weinberg's proband method (Morton, 1959). Using this method, segregation frequencies are calculated (separately for families with $\mathrm{AD}$ and AR pathology) by the ratio of probands; for actually detected patients in families after examination, probability of registration. In our case, the calculated segregation frequencies corresponded to the expected ones -0.25 for the AR type of inheritance and 0.5 for AD. However, it should be noted that the probability of registration differed from $100 \%$ and was $83 \%$ for the group of families with AR pathology and $72 \%$ for $\mathrm{AD}$. The results suggest that irrespective of the total screening performed, a certain number of patients might not have been registered by us.

Point prevalence was calculated according to the procedural document on epidemiology of RDs in Orphanet (2019) as the number of reported cases in the population at a given time point per 100,000 people (all age categories were considered) (European Union (EU), 2009). The prevalence of X-linked pathology was calculated for the male population in the surveyed regions. The average male population in the regions was $46.44 \%$ (variation 45.6-46.9\%).

A nosological registry of detected RHDs based on clinical diagnoses was compiled. For RHD diversity analyses, seven groups were selected with a point prevalence interval of (i) $1: 50,000$ and more frequently, (ii) 1:50,001-1:100,000, (iii) $1: 100,001-1: 200,000$, (iv) $1: 200,001-1: 300,000$, (v) $1: 300,001-$ 1:400,001, (vi) 1:400,001-1:500,002, and (vii) 1:500,001 and less frequently.

Based on clinical manifestations, we additionally analyzed point prevalence according to the generally accepted 
classification of diseases: neurological syndrome, ophthalmic syndrome, genodermatoses, skeletal syndrome, hereditary syndrome, and other pathology (hereditary diseases of metabolism, blood, hearing, etc.).

The methods for collection and processing of medical genetic material remained unchanged throughout all the studies, which allows comparison of newly obtained data with results from the previously surveyed populations of the country.

\section{Molecular Genetic Analysis}

Confirmatory DNA diagnostics was carried out in the laboratories of the RCMG: Laboratory of Genetic Epidemiology (head-R.A. Zinchenko), Laboratory of Epigenetics (headSci. V.V. Strelnikov), and Laboratory of DNA Diagnostics (head-A.V. Polyakov). A variety of methods were used for DNA diagnosis-Sanger sequencing, MLPA, RFLP, AFLP, and whole-exome sequencing-depending on the studied nosology according to the protocols published elsewhere by the authors of the current manuscript (Zinchenko et al., 2020b).

\section{Features and Limitations of the Method}

Monogenic hereditary diseases listed in the OMIM and Orphanet databases with $\mathrm{AD}, \mathrm{AR}$, and X-linked (XL) types of inheritance were included in the analysis. Patients with mitochondrial disorders and chromosomal rearrangements were excluded from the analysis after cytogenetic and molecular genetic studies.

Some patients may not be identified or missed because of the following reasons: (i) patients with subclinical forms of the disease; (ii) patients in the initial stage of the disease with late onset; (iii) patients who refused from examination (from 1 to $5 \%$ ) for various reasons: observation and treatment by a specific physician, unwillingness to disclose their diagnosis, and others; (iv) patients who are not registered in a medical organization of the region; (v) patients who have not passed this examination and do not live in the region (even in familial cases of the disease); (vi) patients who died by the time of the survey; (vii) child patients under 1 year of age with severe hereditary metabolic diseases unable to pass the survey; and (viii) we also assume that due to the increase in the number of confirmed phenotypes at the genetic level in recent years, the recognition of these diseases by physicians of various specialties is not yet possible. There is a lack of knowledge and diagnostic experience, which must inevitably lead to the omission of sporadic cases of rare hereditary diseases. Doctors in all countries face these problems.

The resulting values of the probability of registration are $83 \%$ for the group of families with AR pathology and $72 \%$ for AD.

\section{REFERENCES}

Andreeva, T. V., Tyazhelova, T. V., Rykalina, V. N., Gusev, F. E., Goltsov, A. Y., Zolotareva, O. I., et al. (2016). Whole exome sequencing links dental tumor to an autosomal-dominant mutation in ANO5 gene associated with gnathodiaphyseal dysplasia and muscle dystrophies. Sci. Rep. 6:26440.

Bliznetz, E. A., Tverskaya, S. M., Zinchenko, R. A., Abrukova, A. V., Savaskina, E. N., Nikulin, M. V., et al. (2009). Genetic analysis of autosomal recessive osteopetrosis in Chuvashiya: the unique splice site mutation in TCIRG1 gene spread by the founder effect. Eur. J. Hum. Genet. 17, 664-672. doi: 10.1038/ ejhg.2008.234
We were also unable to estimate the annual incidence (number of newly diagnosed cases in a population within 1 year) due to the lack of this information in medical organizations. In consequence of the above, certain corrections should be made taking into account the limited number of nosological forms envisaged by our study.

\section{DATA AVAILABILITY STATEMENT}

The data analyzed in this study is subject to the following licenses/restrictions: Data are available upon request. Requests to access these datasets should be directed to RZ, renazinchenko@mail.ru.

\section{ETHICS STATEMENT}

The studies involving human participants were reviewed and approved by The Ethical Committee of the Research Centre for Medical Genetics. Written informed consent to participate in this study was provided by the participants' legal guardian/next of kin.

\section{AUTHOR CONTRIBUTIONS}

RZ and EG: conceptualization, methodology, visualization, and funding acquisition. RZ, TV, and OA: validation. RZ, NP, VK, $\mathrm{AP}$, and AM: formal analysis. RZ: resources, data curation, and writing-original draft preparation. AM: writing-review and editing. EG and SK: supervision. RZ, EG, and SK: project administration. All authors have read and agreed to the published version of the manuscript.

\section{FUNDING}

This study was supported by the Russian Science Foundation, grant no. 17-15-01051.

\section{ACKNOWLEDGMENTS}

We thank Richard H. Lozier for interest in our work and useful assistance.

Cavalli-Sforza, L. L., and Bodmer, W. F. (1999). The Genetics of Human Populations. Mineola, NY: Dover Publications.

Dadali, E. L., Makaov, A. K., Galkina, V. A., Konovalov, F. A., Polyakov, A. V., Bulakh, M. V., et al. (2016). Hereditary motor and sensory neuropathy, caused by mutations in the NEFL gene in a family from Karachaevo-Cherkessia. Neuromuscul. Dis. 6, 47-51. (In Russ.), doi: 10.17650/2222-8721-2016-6-247-51

Donnart, A., Viollet, V., and Roinet-Tournay, M. (2013). Les maladies rares, définitions et épidémiologie. Soins Pédiatr. Puéric. 34, 14-16.

Elchinova, G. I., Makaov, A. K., Bikanov, R. A., Gavrilina, S. G., Petrin, A. N., Marakhonov, A. V., et al. (2017). Analysis of the age and sex structure 
of the population of Karachay-Cherkessia Republic. Mod. Probl. Sci. Educ. $2: 52$.

European Union (EU) (2000). Regulation (EC) No 141/2000 of the European Parliament and of the Council of 16 December 1999 on orphan medicinal products. OJEC L18, 1-5.

European Union (EU) (2009). Council recommendation of 8 June 2009 on an action in the field of rare diseases (2009/C 151/02). OJEU C151, 7-10.

Ferreira, C. R. (2019). The burden of rare diseases. Am. J. Med. Genet. A 179, 885-892.

Gundorova, P., Zinchenko, R. A., Kuznetsova, I. A., Bliznetz, E. A., Stepanova, A. A., and Polyakov, A. V. (2018). Molecular-genetic causes for the high frequency of phenylketonuria in the population from the North Caucasus. PLoS One 13:e0201489. doi: 10.1371/journal.pone.0201489

Kazantseva, A., Goltsov, A., Zinchenko, R., Grigorenko, A. P., Abrukova, A. V., Moliaka, Y. K., et al. (2006). Human hair growth deficiency is linked to a genetic defect in the phospholipase gene LIPH. Science 314, 982-985. doi: $10.1126 /$ science. 1133276

Khidiyatova, I. M., Skachkova, I. A., Saifullina, E. V., Magzhanov, R. V., Schagina, O. A., Zinchenko, R. A., et al. (2013). [MFN2 gene analysis in patients with hereditary motor and sensory neuropathy from Bashkortostan Republic]. Genetika 49, 884-890. doi: 10.7868/s0016675813060040

Levchenko, O., Dadali, E. L., Bessonova, L., Demina, N., Rudenskaya, G. E., Matyushchenko, G., et al. (2019). Exome sequencing of 100 patients with intellectual disability. Eur. J. Hum. Genet. 27, S1390-S1391.

Marakhonov, A. V., Konovalov, F. A., Makaov, A. K., Vasilyeva, T. A., Kadyshev, V. V., Galkina, V. A., et al. (2018). Primary microcephaly case from the Karachay-Cherkess Republic poses an additional support for microcephaly and Seckel syndrome spectrum disorders. BMC Med. Genomics 11:8. doi: 10.1186/ s12920-018-0326-1

Marakhonov, A. V., Vasilyeva, T. A., Voskresenskaya, A. A., Sukhanova, N. V., Kadyshev, V. V., Kutsev, S. I., et al. (2019). LMO2 gene deletions significantly worsen the prognosis of Wilms' tumor development in patients with WAGR syndrome. Hum. Mol. Genet. 28, 3323-3326. doi: 10.1093/hmg/ddz168

Morton, N. E. (1959). Genetic tests under incomplete ascertainment. Am. J. Hum. Genet. 11, 1-16.

Murtazina, A. F., Shchagina, O. A., Milovidova, T. B., Dadali, E. L., Rudenskaya, G. E., Kurbatov, S. A., et al. (2020). Clinical and genetic characteristics of Charcot-Marie-Tooth disease type 4D (type Lom) in Russia. Neuromuscul. Dis. 10, 39-45. (In Russ.), doi: 10.17650/2222-8721-2020-10-2-39-45

Wakap, S. N., Lambert, D. M., Olry, A., Rodwell, C., Gueydan, C., Lanneau, V., et al. (2020). Estimating cumulative point prevalence of rare diseases: analysis of the Orphanet database. Eur J Hum Genet 28, 165-173. doi: 10.1038/s41431019-0508-0

Orphanet (2019). Procedural Document on Epidemiology of Rare Disease in Orphanet (Prevalence, incidence and number of published cases or families). February 2019, Version 01. Available online at: https://www.orpha.net/orphacom/cahiers/docs/GB/Epidemiology_in_ Orphanet_R1_Ann_Epi_EP_05.pdf

Pariser, A. R., and Gahl, W. A. (2014). Important role of translational science in rare disease innovation, discovery, and drug development. J. Gen. Intern. Med. 29 Suppl 3, S804-S807.

Petrova, N. V., Kashirskaya, N. Y., Saydaeva, D. K., Polyakov, A. V., Adyan, T. A., Simonova, O. I., et al. (2019a). Spectrum of CFTR mutations in Chechen cystic fibrosis patients: high frequency of c.1545_1546delTA (p.Tyr515X; 1677delTA) and c.274G $>$ A (p.Glu92Lys, E92K) mutations in North Caucasus. BMC Med. Genet. 20:44. doi: 10.1186/s12881-019-0785-z

Petrova, N. V., Kashirskaya, N. Y., Vasilyeva, T. A., Timkovskaya, E. E., Voronkova, A. Y., Shabalova, L. A., et al. (2016). High prevalence of W1282x mutation in cystic fibrosis patients from Karachay-Cherkessia. J. Cyst. Fibros 15, e28-e32.

Petrova, N. V., Marakhonov, A. V., Vasilyeva, T. A., Kashirskaya, N. Y., Ginter, E. K., Kutsev, S. I., et al. (2019b). Comprehensive genotyping reveals novel CFTR variants in cystic fibrosis patients from the Russian Federation. Clin. Genet. 95, 444-447. doi: 10.1111/cge.13477

Richter, T., Nestler-Parr, S., Babela, R., Khan, Z. M., Tesoro, T., Molsen, E., et al. (2015). Rare disease terminology and definitions-A systematic global review: report of the ISPOR rare disease special interest group. Value Health 18, 906-914. doi: 10.1016/j.jval.2015.05.008

Schagina, O. A., Dadali, E. L., Fedotov, V. P., Osipova, E. V., Zinchenko, R. A., Ginter, E. K., et al. (2007). New allelic variant of hereditary motor and sensory neuropathy in big family from Udmurtia. Med. Genet. 6, 33-37. (In Russ.),
Shchagina, O. A., Dadali, E. L., Fedotov, V. P., Milovidova, T. B., Ryzhkova, O. P., and Polyakov, A. V. (2018). Family case of hereditary motor-sensory neuropathy due to the INF2-mutation and hereditary motor and sensory neuropathy with nephrotic syndrome in Russia. Nevrologicheskii Zhurnal 23, 121-127. (In Russ.),

Shchagina, O. A., Milovidova, T. B., Murtazina, A. F., Rudenskaya, G. E., Nikitin, S. S., Dadali, E. L., et al. (2020). HINT1 gene pathogenic variants: the most common cause of recessive hereditary motor and sensory neuropathies in Russian patients. Mol. Biol. Rep. 47, 1331-1337. doi: 10.1007/s11033-01905238-z

Timkovskaya, E. E., Makaov, A. H.-M., Mikhailova, L. K., Vasilyeva, T. A., Marakhonov, A. V., Galkina, V. A., et al. (2016). Metatropic dysplasia: clinical and molecular diagnostics, genetic counseling. Med. News North Cauc. 11, $173-176$.

Vasilyeva, T. A., Marakhonov, A. V., Voskresenskaya, A. A., Kadyshev, V. V., Kasmann-Kellner, B., Sukhanova, N. V., et al. (2021). Analysis of genotypephenotype correlations in PAX6-associated aniridia. J. Med. Genet. 58, 270-274. doi: 10.1136/jmedgenet-2019-106172

Zernov, N. V., Skoblov, M. Y., Marakhonov, A. V., Shimomura, Y., Vasilyeva, T. A., Konovalov, F. A., et al. (2016). Autosomal recessive hypotrichosis with woolly hair caused by a mutation in the keratin 25 gene expressed in hair follicles. J. Invest. Dermatol. 136, 1097-1105. doi: 10.1016/j.jid.2016.0.037

Zinchenko, R. A., El'chinova, G. I., Balanovskaya, E. V., and Al, E. (2000). The influence of population genetic structure on the burden of monogenetic hereditary diseases in Russian Populations. Vestn. Ross. Akad. Med. Nauk. 5, $5-10$.

Zinchenko, R. A., El'chinova, G. I., Baryshnikova, N. V., Polyakov, A. V., and Ginter, E. K. (2007). Prevalences of hereditary diseases in different populations of Russia. Russ. J. Genet. 43, 1038-1045. doi: 10.1134/s1022795407090104

Zinchenko, R. A., Elchinova, G. I., Gavrilina, S. G., and Ginter, E. K. (2001a). Analysis of diversity of autosomal recessive diseases in populations of Russia. Russ. J. Genet. 37, 1312-1322.

Zinchenko, R. A., El'chinova, G. I., and Ginter, E. K. (2009). Factors determining the distribution of hereditary diseases in Russian populations. Med. Genet. 8, $7-23$.

Zinchenko, R. A., Elchinova, G. I., Nurbaev, S. D., and Ginter, E. K. (2001b). Diversity of autosomal dominant diseases in populations of Russia. Russ. J. Genet. 37, 290-301.

Zinchenko, R. A., Kadyshev, V. V., Galkina, V. A., Dadali, E. L., Mikhailova, L. K., Marakhonov, A. V., et al. (2019). Clinical population genetics of hereditary diseases among children of the karachay-cherkess republic. Russ. J. Genet. 55, 1033-1040. doi: 10.1134/s1022795419080180

Zinchenko, R. A., Kadyshev, V. V., Galkina, V. A., El'chinova, G. I., Marakhonov, A. V., Alexandrova, O. Y., et al. (2020a). The load and diversity of monogenic hereditary pathology among the children's population of the Kirov region. Russ. J. Genet. 54, 1530-1534. doi: 10.1134/s1022795420120157

Zinchenko, R. A., Makaov, A. K., Marakhonov, A. V., Galkina, V. A., Kadyshev, V. V., El'chinova, G. I., et al. (2020b). Epidemiology of hereditary diseases in the karachay-cherkess republic. Int. J. Mol. Sci. 21:325.

Conflict of Interest: The authors declare that the research was conducted in the absence of any commercial or financial relationships that could be construed as a potential conflict of interest.

The reviewer MM declared a past co-authorship with the authors RZ, EG, AM, NP, TV, and SK to the handling editor.

Publisher's Note: All claims expressed in this article are solely those of the authors and do not necessarily represent those of their affiliated organizations, or those of the publisher, the editors and the reviewers. Any product that may be evaluated in this article, or claim that may be made by its manufacturer, is not guaranteed or endorsed by the publisher.

Copyright (C) 2021 Zinchenko, Ginter, Marakhonov, Petrova, Kadyshev, Vasilyeva, Alexandrova, Polyakov and Kutsev. This is an open-access article distributed under the terms of the Creative Commons Attribution License (CC BY). The use, distribution or reproduction in other forums is permitted, provided the original author(s) and the copyright owner(s) are credited and that the original publication in this journal is cited, in accordance with accepted academic practice. No use, distribution or reproduction is permitted which does not comply with these terms. 